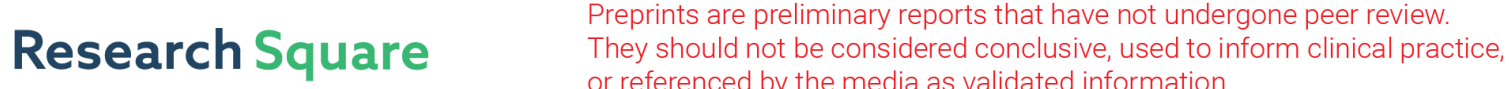 or referenced by the media as validated information. \\ Yield Advantage of a Maize-peanut Intercropping System
}

\section{Yan-hong Li}

Soil Fertilizer Station of Yantai Agricultural Technology Promotion Center,China

Lei Wang

Shandong Agricultural University

\section{De-yang Shi}

Yantai Academy of Agricultural Sciences

Shu-ting Dong ( $\nabla$ stdong@sdau.edu.cn )

Shandong Agricultural University

\section{Research Article}

Keywords: Intercropping system, Summer maize, Peanut, Yield, Economic benefits

Posted Date: February 4th, 2021

DOl: https://doi.org/10.21203/rs.3.rs-163681/v1

License: @ (i) This work is licensed under a Creative Commons Attribution 4.0 International License. Read Full License 


\title{
Yield advantage of a maize-peanut intercropping system
}

\author{
Li Yan-hong ${ }^{1,2}$, Wang Lei ${ }^{1}$, Shi De-yang1,3 \& Dong Shu-ting ${ }^{1, *}$ \\ ${ }^{1}$ Shandong Agricultural University, China. ${ }^{2}$ Soil Fertilizer Station of Yantai Agricultural \\ Technology Promotion Center,China, China. ${ }^{3}$ Yantai Academy of Agricultural Sciences, China. \\ Correspondence and requests for materials should be addressed to Dong Shu-ting (email: \\ stdong@sdau.edu.cn)
}

\begin{abstract}
\end{abstract}
Maize-peanut intercropping is an important element of China's agricultural planting model, as it confers ecological benefits, promotes species diversity, and increases economic efficiency and yield. The aim of this study was to explore the yield differences between intercropping and monoculture, and to determine the mechanism underlying the high yield efficiency of the intercropping system using the ${ }^{13} \mathrm{C}$ isotope tracer labelling method. The early maturing corn hybrid Denghai 618 and the early maturing and high-yielding peanut variety Huayu 22 were used as test materials. Three kinds of planting methods were employed, i.e. the sole maize (SM), the sole peanut (SP) and maize-peanut intercropping (intercropped maize, IM; intercropped peanut, IP), for two consecutive years. IM increased yield by $59.7 \%$ and $62.3 \%$ comparing with SM in 2015 and 2016, respectively. IP reduced yield by $31.3 \%$ and 32.3\% comparing with SP in 2015 and 2016, respectively. IM significantly increased the photosynthetic rate, leaf area, ${ }^{13} \mathrm{C}$ assimilation distribution, and dry matter accumulation of summer maize, which led to an increase in kernel number, resulting in an increased yield. The decrease in intercropped peanut yield was mainly caused by a decrease in the percent of plump pod and number of pods per plant. The decrease in peanut yield did not affect the production of intercropping, because of the large 
intercropping advantage and land equivalence ratio. Maize-peanut intercropping provided greater economic benefits than monoculture. These results showed the utility of the peanut-maize intercropping model.

Keywords: Intercropping system; Summer maize; Peanut; Yield; Economic benefits

\section{Introductions}

The rapid industrialization of the agricultural sector is conducive to increased labor productivity and crop yields, meanwhile it also brings many ecological problems, including loss of biodiversity, reduced soil fertility, and increased pollution caused by the intensive use of chemical fertilizers and pesticides (Jacobsen et al., 2013). In recent years, the Chinese government has paid more and more attention to the ecological benefits of agriculture, requiring the reduction in the use of fertilizer and pesticide in agricultural production and prohibition of straw burning. To ensure both food security and ecological benefits, it is essential to seek best management practices, which include appropriate cropping systems that can efficiently utilize solar and soil resources with minimum nutrient inputs.

Intercropping is a farming practice involving two or more crop species, or genotypes, growing together and coexisting for a time with a definite row arrangement. (Carrubba.et al., 2008; Bedoussac et al., 2015). Compared with its component monocrops, it is reported to deliver pest control, optimize field microclimate, similar yields with reduced inputs, pollution mitigation, greater or more stable aggregate food or forage yields per unit area and complementary use of scare resources, $\mathrm{N}$ fixation are also very improtant principles of intercropping (Zhu et al., 2000; Lithourgidis et al., 2011; Smith et al., 2013). However, not all intercropping systems provide benefits in terms of all possible metrics. For example, legume-cereal mixtures often provide 
higher biomass and protein yields than sole cropped cereals (Anil et al., 1998), and the inability to apply certain herbicides can cause greater weed control issues with intercropping compared to monocrop (Moss et al., 2012). When intercropping benefits do occur, they emerge from more complete exploitation of resources, such as solar radiation, water, soil and fertilizers, from beneficial neighbour interactions, and in some cases from continuous soil cover (Vandermeer et al., 1990; Munz et al., 2014). Therefore, it is helpful to improve the intercropping effect by co-allocating crops with different planting types and growing periods, and via unequal plant spacing in the field.

Cereals and legume intercropping has been widely used in the world in virtue of its interspecific promotion and niche complementation among numerous intercropping combinations, (Zhang et al., 2015). Almost all published reports on legume-cereal intercropping documented yield advantages compared with the corresponding monocultures (Misra et al., 2006; Zhang et al., 2011). In addition, legume-cereal intercropping is a practical method to conserve soil and to increase economic returns (Diebel et al., 1995; Clark et al., 1998; Smith and Carter, 1998). Furthermore, intercropping agroecosystem has greater production stability than conventional monocultures (Wells et al., 2000; Skelton and Barrett, 2005). In China, maize (Zea mays L.) is the first major grain crops, and peanut (Arachis hypogaea L.) is the major oilseed crop, which accounting for $30 \%$ of the total oilseed production in the country (Shen et al., 2014). Maize-peanut intercropping is a typical intercropping combination between grasses and legumes, which can significantly alleviate the competition for land between grain and oil and achieve synchronous increases in the yields of grain crops and oil crops (Wang et al.,2020;Zhang et al., 2020). Maize and peanut, as tall and short plants, can be alternately planted to form an umbrella 
structure that is conducive to improving light transmittance and light energy interception rates (Maddonni et al., 2001; Awal et al., 2006). As the higher crop, the available space, light intensity, photosynthetic rate of functional leaves of intercropped maize increased significantly than that of monoculture maize (Jiao et al., 2006; 2013); moreover, intercropping increases the chlorophyll content and changes the chlorophyll composition, which is mainly manifested in the significant increase in the content of chlorophyll and carotenoidsprolonged the active photosynthetic duration of maize functional leaves (Jiao et al., 2008). This study assessed maize and peanut in field experiments, in terms of their physiological traits, yields, assimilate distributions, and dry matter accumulation characteristics. The objectives of this work were (i) to determine the yield and economic benefits associated with maize-peanut intercropping; (ii) to investigate the influence of intercropping on the photosynthetic productivity of maize; and (iii) to evaluate the accumulation and distribution of ${ }^{13} \mathrm{C}$-photosynthate with the ${ }^{13} \mathrm{CO} 2$ stable isotope tracer to obtain an improved understanding of the effect of intercropping on maize yield. This study will provide valuable information for the adjustment of agricultural structure and sustainable development of agriculture.

\section{Methods}

\section{Experimental design and crop management}

This study was conducted at the State Key Laboratory of Crop Biology and the Experimental Farm of Shandong Agricultural University, China $\left(36^{\circ} 11^{\prime} \mathrm{N}, 117^{\circ} 06^{\prime} \mathrm{E}, 151 \mathrm{~m}\right.$ above sea level) in the period of 2015-2016. This region was characterised by brown loamy soil and a temperate continental monsoon climate, with an average annual temperature of approximately $13^{\circ} \mathrm{C}$, an average frost-free period of $195 \mathrm{~d}$, and average annual precipitation of $697 \mathrm{~mm}$, mainly from June 
to August. The changes in the climate observed during the maize growing season were shown in Fig. 1.

Soil physical and chemical parameters were measured in the $0-20 \mathrm{~cm}$ soil layer before sowing in 2015: $\mathrm{pH}(6.3)$, organic matter $\left(11.2 \mathrm{~g} \mathrm{~kg}^{-1}\right)$, total nitrogen $\left(0.92 \mathrm{~g} \mathrm{~kg}^{-1}\right)$, available phosphorus $\left(47.1 \mathrm{mg} \mathrm{kg}^{-1}\right)$, and available potassium $\left(84.2 \mathrm{mg} \mathrm{kg}^{-1}\right)$. The early maturing corn hybrid Denghai 618 (DH618), and the early maturing and high-yielding peanut cultivar Huayu 22 (HY22), were the test crops in this study.

Three kinds of planting methods were used, i.e. the sole maize (SM), sole peanut (SP) and maize-peanut intercropping (intercropped maize, IM; intercropped peanut, IP), which were applied in two consecutive years. SP was planted in equally spaced rows with a density of 180,000 holes $\mathrm{ha}^{-1}$; there were two seeds per hole, with row spacing of $35 \mathrm{~cm}$ and plant spacing of $16 \mathrm{~cm}$. The SM planting density was 105,000 plants $^{-1} \mathrm{a}^{-1}$, with row spacing of $60 \mathrm{~cm}$ and plant spacing of 15.9 $\mathrm{cm}$. For the intercropping system, the planting ratio was $4: 6$, i.e. four rows of maize to six rows of peanut. With this row-ratio design, the two crops cover a similar area, which facilitates rotation of the two crops to eliminate continuous peanut obstacles. The maize and peanut were planted at the same density in the intercropping system as used in their respective monocultures. The spacing between crops in the intercropping system was $50 \mathrm{~cm}$, and the bandwidth was $455 \mathrm{~cm}$ (Fig. 2). The plot size was $6 \mathrm{~m}$ in width by $30 \mathrm{~m}$ in length in SM, $7 \mathrm{~m}$ in width by $30 \mathrm{~m}$ in length in SP, and $13.65 \mathrm{~m}$ in width by $30 \mathrm{~m}$ in length in the maize-peanut intercropping system. The row orientation was north-south, the experimental design was a completely randomized design with three times repetition. Furthermore, the spacing between the single crop system was $300 \mathrm{~cm}$. In the pure crop plots, we discard the external two rows of both corn and peanut due to potential 
111 border effects, to eliminate differences among duplications, six rows of peanut and then several

112 rows of maize were planted at the left of the maize/peanut intercropping system, and four rows of

113 maize and then several rows of peanut were planted at the right of the intercropping system. In

114 both growing seasons, maize and peanut were supplied with 200 and $45 \mathrm{~kg} \mathrm{~N} \mathrm{ha}^{-1}$ in resin-coated

115 urea $(43 \% \mathrm{~N})$, respectively, and both crops were supplied with $100 \mathrm{~kg}_{2} \mathrm{O}_{5}$ ha $^{-1}$ in calcium

116 superphosphate $\left(12 \% \mathrm{P}_{2} \mathrm{O}_{5}\right)$ and $120 \mathrm{~kg} \mathrm{~K}_{2} \mathrm{O}$ ha $\mathrm{a}^{-1}$ in potassium chloride $\left(62 \% \mathrm{~K}_{2} \mathrm{O}\right)$. All $\mathrm{N}$, $\mathrm{P}$ and

$117 \mathrm{~K}$ fertilizers for both crops were applied as basal fertilizers. Maize and peanut were sown and

118 harvested at the same time; they were sown on 10 June 2015 and 2016, and harvested on 5

119 October 2015 and 2016.

120 Weeds were controlled chemically (Refined iso-alachlor, a pre-emergence herbicide can

121 be used for maize and peanuts) before maize and peanut emergence. Diseases and insect pests of

122 maize and peanut were controlled by conventional techniques using an isolation belt spraying

123 machine. Supplementary water was applied during the growing season according to the estimation

124 of weekly plant water demand (evapotranspiration) and precipitation.

\section{Sampling and measurements}

et al., 1993) was estimated based on 30 consecutive plants in each row. All grain was air-dried to investigate yield as follows: 
strip and air-dried; the yield, 100-kernel weight, pods per plant, and the percent of plump pod were then determined.

\section{The land equivalence ratio (LER) and Intercropping advantage}

Maize and peanut intercropping performance was assessed according to the LER:

$$
\operatorname{LER}=\left(Y_{i m} / Y_{s m}\right)+\left(Y_{i p} / Y_{s p}\right)
$$

Where $Y_{i m}$ and $Y_{i p}$ indicate the actual yield of intercropped maize and intercropped peanut, respectively. $Y_{s m}$ and $Y_{s p}$ are the yield of SM and SP, respectively. An LER value > 1 indicates that intercropping is advantageous and LER $<1$ indicates that intercropping is disadvantageous.

$$
\text { Intercropping advantage }=Y_{i}-\left(Y_{s m} \times F_{m}+Y_{s p} \times F_{p}\right)
$$

$Y_{i}$ indicates the yield of the intercropping system, and $Y_{i}=Y_{i m}+Y_{i p} ; F_{m}$ and $F_{p}$ represent the proportion of area between the intercropped maize and peanut, respectively.

\section{Economic benefit}

Economic benefit (USD ha ${ }^{-1}$ ) was calculated according to:

$$
\text { Economic benefit }=\mathrm{Y} \times \mathrm{P}-\mathrm{LF}-\mathrm{FF}-\mathrm{SF}-\mathrm{PF}
$$

where $\mathrm{Y}$ is yield $\left(\mathrm{kg} \mathrm{ha}^{-1}\right), \mathrm{P}$ is grain price $\left(\mathrm{USD} \mathrm{ha}{ }^{-1}\right), \mathrm{LF}$ is labor fees (USD ha-1), FF is fertilizer fees (USD ha ${ }^{-1}$ ), SF is seed costs (USD ha-1) and BF is pesticide expenses (USD ha ${ }^{-1}$ ). USD is U.S. dollar.

\section{d (tasselling stage; VT), 68 d (blister stage; R2), 90 d (dough stage; R4) and 117 d (R6) after} sowing, and four representative peanut plants were sampled in each plot on $30 \mathrm{~d}$ (beginning peg stage), $58 \mathrm{~d}$ (full pod stage), $88 \mathrm{~d}$ (full seed stage) and $117 \mathrm{~d}$ (harvest maturity stage, Boote, 1982) 
after sowing to determine dry matter. These maize plants (aboveground) and peanut plants (including aboveground, roots and pods) were dried at $80^{\circ} \mathrm{C}$ in a forced-draft oven (DHG-9420A; Bilon Instruments Co. Ltd., Shanghai, China) to a constant weight.

\section{Net photosynthetic rate (Pn) and Leaf area index (LAI)}

Pn was measured with a portable gas exchange system (CIRAS-2, PP Systems, UK) equipped with a square $\left(2.5 \mathrm{~cm}^{2}\right)$ chamber. The photosynthetic photon flux density (PPFD), provided by an internal light source from the leaf chamber, was $1600 \mu \mathrm{mol} \mathrm{m} \mathrm{m}^{-2} \mathrm{~s}^{-1}$, and the leaf temperature was a relatively constant $30^{\circ} \mathrm{C}$ (Wang et al., 2009). The measurements were done at the V12, VT, R2, R4, and R6 stage for maize and at the beginning peg, full pod, full seed and harvest maturity stage for peanut in cloudless days.

\section{Ten plants showing similar growth were selected during the maize growing season to}

determine leaf area during V12, VT, R2, R4, and R6.

$$
\mathrm{LAI}=(\text { Single plant leaf area } \times \text { plot number }) / \text { plot area }
$$

The leaf area of peanut was determined by the specific leaf weight method.

$$
\mathrm{S}=\frac{(M 1+M 2)}{\left(\frac{M 1}{S 1}\right)}
$$

Where $\mathrm{S} 1$ is green blades of a fixed area; M1 is the dry weight of green blades with a fixed area; $\mathrm{M} 2$ is the dry weight of the remaining leaf area; and $\mathrm{S}$ is the total leaf area.

\section{Distribution and accumulation of assimilation products}

Ten representative plants were selected during the 2015 and 2016 maize silking periods. Their ear leaves were sealed and ${ }^{13} \mathrm{CO}_{2}$ feeding was carried out immediately to maintain photosynthesis for $60 \mathrm{~min}$. Five plants were obtained after $24 \mathrm{~h}$ and during R6, and the organs were dried in the oven and weighed with an electronic balance. The ${ }^{13} \mathrm{C}$ abundance was [键入文字] 
determined by a stable isotope mass spectrometer (ISOPRIME100) and the accumulation and distribution of ${ }^{13} \mathrm{C}$ assimilates in the aboveground organs were calculated.

\section{Statistical analysis}

Data were analysed using Microsoft Excel (Microsoft Corp., Redmond, WA, USA), SigmaPlot (ver. 11.0; Systat Software, San Jose, CA, USA) and SPSS (ver. 16.0; SPSS Inc., Chicago, IL, USA) software. All measured and calculated features were analyzed as dependent variable; cropping treatments was analyzed as fixed factors. Significant differences among means were determined by Duncan's multiple range test at $5 \%$ level.

\section{Results}

\section{Yield and economy advantage of intercropping system}

Compared to monoculture, maize-peanut intercropping system had intercropping advantages in yield and economy (i.e., promoted crop yield and farmers' income) (Table 1). Under the same planting area, IM increased production by 59.7\% and 62.3\% in 2015 and 2016, respectively, compared with SM, while IP reduced production by 31.3\% and 32.3\% in 2015 and 2016, respectively, compared with SP. Maize-peanut had the highest economic benefit among all the cropping systems with $385.5 \mathrm{USD} \mathrm{ha}^{-1}$ greater than SM and 585.5 USD ha-1 greater than SP over the two growing seasons. In addition, the intercropping system had a LER value greater than that in both growing seasons.

\section{Yield composition of maize and peanut}

Intercropping significantly affected the yield components of maize and peanut (Table 2). Ear number (expressed per unit area of the whole system) was significantly lower in intercrops than in SM, while kernel number and 1000-grain weight were significantly greater in intercrops than in SM, which indicated that the advantage of intercropping was due mainly to the increase in maize yield per plant. Averaged the two growing seasons, the kernel number and 1000-grain weight of [键入文字] 
IM were increased by $20.0 \%$ and $8.0 \%$ compared to SM, respectively. The pod number per plant, 100-pod weight and percent of plump pod of the peanut grown in intercrops treatment were lower than that in monoculture, with decreased by $2 \%, 12.9 \%$ and $28.6 \%$ over the two years.

\section{Dry matter accumulation and LAI}

IM significantly increased the accumulation of dry matter after anthesis compared with SM, which was more evident during the maize late filling stage (R4-R6). Dry matter accumulation per maize of IM at the R6 stage significantly increased by 20.9\% compared with SM in 2015, whereas dry matter accumulation per maize was $16.9 \%$ significantly greater in IM compared with SM during 2016 (Fig. 3). IP significantly reduced dry matter accumulation per peanut compared with SP in 2015. Dry matter accumulation per peanut at the harvest stage significantly decreased by 13.4\% with IP compared with SP, while dry matter accumulation per peanut in 2016 significantly decreased by $11.7 \%$ with the former method.

LAI significantly increased by $15.2 \%$ with IM at R6 stages during 2015 compared with SM, while there was little difference in 2016 with only $5.3 \%$ increased. The LAI of peanut at the harvest stage significantly decreased by $16.5 \%$ with IP during 2015 compared with SP, while LAI decreased significantly by $13.8 \%$ with IP during 2016 compared with SP (Fig. 4).

\section{Net photosynthetic rate $(P n)$}

Intercropping increased the $P$ n of maize significantly in different growing stages in both seasons (Fig. 5). With the development of the growing stage, the $P$ n of ear leaves of SM and IM showed a single-peak trend, reaching its maximum at R2, and then decreasing. Averaged over the two seasons, the Pn of IM at R2 significantly increased by $6.5 \%$ compared with SM. The photosynthetic rate of peanut tended to decrease as growth proceeded. IP significantly reduced the 
photosynthetic rate of peanut during the entire growth period, which was due to the shading effect of maize, as a high-stalk crop, on the photosynthetic rate of peanut.

\section{Distribution and accumulation of assimilated matter}

Intercropping treatment altered the pattern of distribution of ${ }^{13} \mathrm{C}$-photosynthates among different organs (Table 3). At the silking and after $24 \mathrm{~h}$ of isotope tracer labelling, the maximum ratio of distribution was recorded in the stem followed by leaves. At R6, the distribution of ${ }^{13} \mathrm{C}$-photosynthates was mainly concentrated in the grains. Relative to the $\mathrm{SM},{ }^{13} \mathrm{C}$-photosynthates distribution in grain increased by $3.6 \%$ in IM, averaged the two growing seasons.

\section{Discussion}

Intercropping improved resource acquisition and productivityrelative comparied to monoculture(Giles et al., 2017). Complementarity is likely as intercropped maize uses $\mathrm{N}$ from the soil for growth whilst the legume canrely more on atmospheric $\mathrm{N}_{2}$ fixation for growth. These can be influenced by soil fertility status, spatial planting arrangements and choice of intercrop components(Kermah et al., 2017). The main reason for farmers in China to practice intercropping is that it can increase land productivity and profitability (Feike et al., 2010; Odhiambo et al., 2011). This study clearly demonstrated that intercropping systems presented advantage over maize or peanut monoculture. Maize/peanut system showed intercropping advantages in yield, economy and land utilization ratio. Previous studies had also reported beneficial effects of intercropping systems on yield, economy and the environment (Zhang et al., 2011; Rusinamhodzi et al., 2012; Li et al., 2013; Meng et al., 2016), which stresses the importance of using intercropping in sustainable agriculture to alleviate pressure in intensive farming systems with high inputs and outputs ( $\mathrm{Li}$ et al., 2010). In this study, we found that land use efficiency, measured by the LER, 
varied from 1.15 to 1.16 over the two growing seasons (Table 1); intercropping greatly increased land use efficiency, which indicated that maize and peanut intercropping is a compound system with high quality, high yield and high efficiency. It can not only increase grain yield, but also increase farmers' income, alleviate the contradiction between grain and oil.

The photosynthetic physiological characteristics of crops are the core element of plant production and the most important physiological processes in plants. The photosynthetic characteristics of plants have an important effect on growth and development (Covshoff and Hibberd 2012). Sufficient light is important for high and steady yields, particularly in maize, which is a typical $\mathrm{C}_{4}$ plant (Gao et al., 2017). Lv et al. (2014) reported that the advantage of intercropping was probably derived from high light use efficiency above-ground and nutrients (e.g., N) below-ground. Maize-peanut intercropping can improve the population structure, which make the leaves of maize on different levels enjoy appropriate sun radiation, delay the aging of leaves and increase the chlorophyll content of ear leave as well as net photosynthetic rate (Jiao et al., 2008). Similar result was obtained in this study; the ability of intercropped maize to capture sunlight was enhanced, which was manifested by the increased LAI, Pn and dry matter accumulation. However, affected by the shading of maize, the intercropping peanut was long in the disadvantage of light. The net photosynthetic rate, dry matter accumulation and LAI of IP were lower compared with the SP in this study, which was consistent with Jiao et al. (2008), who reported that the light compensation point and light saturation point of the functional leaf in intercropped peanut decreased. As a result, maize yield of intercropping system was significantly increased, while the pod yield of IP decreased over the 2-yr study period, which was consistent with previous studies (Jiao et al., 2008). Intercropped legume probably facilitated growth of grass 
by transferring the $\mathrm{N}$ fixed (Li et al., 2009; Seran and Brintha, 2010; Altieri et al., 2012), which may be another reason for the increased maize yield in the intercropping system.

An efficient way to assess the contribution of each part of a maize plant to grain yield is by assessing the amount of ${ }^{13} \mathrm{CO}_{2}$ fixed in the plant and transferred to each of its parts, although total

${ }^{13} \mathrm{C}$ fixed was underestimated in a previous study because the amount of ${ }^{13} \mathrm{C}$ lost to the soil was not measured (Wu et al., 2010). The results of a ${ }^{13} \mathrm{C}$ tracer study showed that assimilates were mainly concentrated in grains during the mature period of maize, and that stem and leaf assimilation products were transferred to the grains (Table 3). Under the intercropping system, maize was more assimilated to grain than under the SP system, which laid the foundation for an increase in the intercropped maize yield and had a positive effect on grain filling.

Intercropping improves crop colony structure, enhances the land utilization ratio and enhances resistance at the group level; it also reduces fertilizer and has remarkable economic (Table 1), environmental and social benefits. Intercropping is thus valuable for food security at the national level and helps to improve the market competitiveness of agricultural products. Our next step will be to conduct detailed studies on the effects of the intercropping system on soil microenvironment and community structure.

\section{Conclusion}

Maize played an important role in determining the yields in the intercropping system; it was the dominant and superior crop and had a stronger ability to obtain resources than peanut when intercropped. Compared to conventional monoculture of maize, the maize-peanut intercropping had significant advantage in yield and land utilization ratio, due to the improved canopy structure of crop population, which make the leaves of maize on different levels enjoy appropriate sun 
radiation, and the optimized distribution and utilization of assimilation during the later stage of crop production. In contrast, the IP method significantly decreased yield compared with SP,

291 primarily because the long-term exposure to maize shading. Maize-peanut intercropping system

292 yielded greater economic benefits and land use efficiency than monoculture, which provides 293 strong justification for widespread adoption of this cultivation method in the Huang-Huai-Hai 294 Plains.

\section{References}

Altieri, M.A, Funes-Monzote, F.R., Petersen, P., 2012. Agroecologically efficient agricultural systems for smallholder farmers: contributions to food sovereignty. Agron. Sustain. Dev. 32: 1-13.

Anil, L., Park, J., Phipps, R. H., Miller, F. A., 1998. Temperate intercropping of cereals for forage: a review of the potential for growth and utilization with particular reference to the UK. Grass and Forage Science 53,

Awal, M.A., Koshi, H., Ikeda, T. 2006. Radiation interception and use by maize/peanut intercrop canopy. Agr

Boote, K. J. 1982. Growth stages of peanut. Peanut Sci, 9: 35-40.

Clark, M.S., Ferris, H., Klonsky, K., Lanini, W.T., Van Bruggen, A., Zalom, F.G., 1998. Agronomic, economic, and

Carrubba, A., Torre, R.L., Saiano, F., Aiello, P. 2008. Sustainable production of fennel and dill by intercropping. Agron. Sustain. Dev. 28(2): 247-256. environmental comparison of pest management in conventional and alternative tomato and corn systems in 
northern California. Agric. Ecosyst. Environ. 68, 51-71.

Giles, C. D. , Brown, L. K. , Adu, M. O. , Mezeli, M. M. , Sandral, G. A. , \& Simpson, R. J. Response-based selection of barley cultivars and legume species for complementarity: Root morphology and exudation in relation to nutrient source. Plant Sci, 225,12-18.Covshoff, S., Hibberd, J.M. 2012. Integrating $\mathrm{C}_{4}$ photosynthesis into $\mathrm{C}_{3}$ crops to increase yield potential. Curr. Opin. Biotech. 23(2), 209-214.

Diebel, P.L., Williams, J.R., Llewelyn, R.V., 1995. An economic comparison of conventional and alternative cropping systems for a representative northeast Kansas farm. Rev. Agric. Econ. 17, 323-335.

Feike, T., Chen, Q., Penning, J., Graeff-Honninger, S., Zuhlke, G., Claupein, W., 2010. How to overcome the slow death of intercropping in China. Building Sustainable Rural Futures. Proceedings of the 9th European IFSA Symposium, Vienna, Austria, 2149-2158.

Gao, J., Zhao, B., Dong, S.T., Liu, P., Ren, B.Z., Zhang, J.W. 2017. Response of summer maize photosynthate accumulation and distribution to shading stress assessed by using ${ }^{13} \mathrm{CO}_{2}$ stable isotope tracer in the field. Front. Plant Sci.8. 1821. doi: 10.3389/fpls.2017.01821

Jacobsen, S.E., Sorensen, M., Pedersen, S.M., Weiner, J. 2013. Feeding the world: genetically modified crops versus agricultural biodiversity. Agron. Sustain. Dev. 33(4), 651-662.

Jiao, N.Y., Ning, T. Y., Yang, M. K., Fu, G.Z., Yin, F., Xu, G.W., Li, Z.J., 2013. Effects of maize $\|$ peanut intercropping on photosynthetic characters and yield forming of intercropped maize. Acta Ecologica Sinica, 33(14), 4324-4330. (in Chinese)

Jiao, N.Y., Ning, T.Y., Zhao, C. 2006. Characters of photosynthesis in intercropping system of maize and peanut. Acta Agron Sin. 32, 917-923 (in Chinese with English abstract).

Jiao, N.Y., Zhao, C., Ning, T.Y., Hou, L.T., Fu, G.Z., Li, Z.J., Chen, M.C., 2008. Effects of maize-peanut intercropping on economic yield and light response of photosynthesis. Chinese Journal of Applied Ecology. 
Kermah, M. , Franke, A. C. , Adjei-Nsiah, S. , Ahiabor, B. D. K. , Abaidoo, R. C. , \& Giller, K. E. Maize-grain legume intercropping for enhanced resource use efficiency and crop productivity in the Guinea savanna of northern Ghana. Field Crops Res, $213,38-50$

Li, L., Zhang, L.Z., Zhang, F.Z., 2013. Crop mixtures and the mechanisms of overyielding. In: Levin SA, ed. Encyclopedia of biodiversity, 2nd edn, vol, 2. Waltham, MA, USA: Academic Press, 382-395.

Li, Q.Z., Sun, J.H., Wei, X.J., Christie, P., Zhang, F.S., Li, L. 2010. Over yielding and interspecific interactions

Lv, Y., Francis, C., Wu, P.T., Chen, X.L., Zhao, X.N., 2014. Maize-soybean intercropping interactions above and

Lithourgidis, A.S., Dordas, C.A., Damalas, C.A., Vlachostergios, D.N., 2011. Annual intercrops: an alternative pathway for sustainable agriculture. Aust. J. Crop. Sci. 5, 396-410.

Li, Y.F., Ran, W., Zhang, R.P., Sun, S.B., Xu, G.H., 2009. Facilitated legume nodulation, phosphate uptake and nitrogen transfer by arbuscular inoculation in an upland rice and mung bean intercropping system. Plant and Soil. 315:285-296.

\footnotetext{
xiN. 2014. Maze-soybean inerciopping ineractons above and
} below ground. Crop Sci. 54(3), 914-922.

Maddonni, G.A., Otegui, M.E., Cirilo, A.G. 2001. Plant population density, row spacing and hybrid effects on maize canopy architecture and light attenuation. Field Crops Res.71(3), 183-193.

Meng, W.W., Gao, H.X., Zhang, Z., Xia, H.Y., Liu, L.Y., Guo, F., Li, Z.X., Wan, S.B., 2016. Effects of different maize/peanut intercropping modes on system yield and land equivalent ratio. Shandong Agricultural Sciences. 48(12), 32-36. (in Chinese)

Misra, A.K., Acharya, C.L., Rao, A.S., 2006. Interspecific interaction and nutrient use in soybean/sorghum 
Moss, J. W., Tubbs, R.S., Grey, T.L., Smith, N.B., Johnson, J.W., Davis, J.W., 2012. Agronomic and economic comparisons of double-crop and relay-intercropping systems of peanut with wheat. Crop Management,

Munz, S., Graeff-Hönninger, S., Lizaso, J.I., Chen, Q., Claupein, W. 2014. Modeling light availability for a subordinate crop within a strip-intercropping system. Field Crops Res. 155(155), 77-89.

Odhiambo, J.A., Vanlauwe, B., Tabu, I.M., Kanampiu, F., Khan, Z., 2011. Effect of intercropping maize and soybeans on striga hermonthica parasitism and yield of maize. Arch. Phytopathol. Pflanzenschutz, 44(2),

Ritchie, S.W., Hanway, J.J., Benson, G.O., Herman, J.C. and Lupkes, S.J. 1993. How a corn plant develops. Ext 
Smith, M.A., Carter, P.R., 1998. Strip intercropping corn and alfalfa. J. Prod. Agr. 11, 345-352.

Takim, F.O. 2012. Advantages of maize-cowpea intercropping over sole cropping through competition indices. Jour. Agr. Bio. Res.1(4), 53-59.

Vandermeer, J.H., Caroll, C.R., Vandermeer, J.H., Rosset, P.M. 1990. Intercropping. Field Crops Res. 34(93), 239-245.

Wang R , Sun Z, Zhang L, et al. Border-row proportion determines strength of interspecific interactions and crop yields in maize/peanut strip intercropping. Field Crops Res, 253,107819.

Wang, R.F., An, D.G., Xie, Q.E., Jiang, G.M., Wang, K.J.2009. Leaf photosynthesis is enhanced in normal oil maize pollinated by high oil maize hybrids. Ind. Crop. Prod. 29,182-188.

Wells, A.T., Chan, K.Y., Cornish, P.S., 2000. Comparison of conventional and alternative vegetable farming systems on the properties of a yellow earth in New South Wales. Agric. Ecosyst. Environ. 80, 47-60.

Wu, W.X., Liu, W., Lu, H.H., Chen, Y.X., Medha, D., Janice, T. 2010. Use of ${ }^{13} \mathrm{C}$ labeling to assess carbon partitioning in transgenic and nontransgenic (parental) rice and their rhizosphere soil microbial communities. FEMS Microbiol Ecol. 67(1), 93-102.

Zhang D, Sun Z, Feng L, et al. Maize plant density affects yield, growth and source-sink relationship of crops in maize/peanut intercropping[J]. Field Crops Res.257,107926.

Zhang, G.G., Yang, Z.B., Dong, S.T., 2011. Interspecific competitiveness affects the total biomass yield in an alfalfa and corn intercropping system. Field Crops Res. 124, 66-73.

Zhang, Y.Q., Yang, H., Qi, Z.Y., Yuan, L., Wang, N., Jin, C., Qiu, Z.G., 2011. Effect of light stress on the plant characters of maize inbred lines. Chinese Agricultural Science Bulletin, 27(33), 40-43. (in Chinese)

Zhang, Y.T., Liu, J., Zhang, J.Z., Liu, H.B., Liu, S., Zhai, L.M., Wang, H.Y., Lei, Q.L., Ren, T.Z., Yin, C.B., 2015. Row ratios of intercropping maize and soybean can affect agronomic efficiency of the system and 


\section{Acknowledgements} and 31171497) and the Shandong "Double Tops" Program (SYL2017XTTD14). Our classmates are acknowledged for helping us to improve the original manuscript.

\section{Author Contributions Statement}




\section{Figures}

423 Fig. 1 Annual meteorological data in 2015 and 2016

424 Fig. 2 Sketch map of maize-peanut intercropping pattern

425 Fig.3 Effects of planting pattern on the dry matter accumulation per plant of maize and peanut $\left(\mathrm{g} \mathrm{plant}^{-1}\right)$

426 Fig.4 Effects of planting pattern on the LAI of maize and peanut

427 Fig.5 Effects of planting pattern on the net photosynthetic rate $(P n)$ of maize and peanut 
430 Table 1. Crop yield, economic benefit, intercropping advantage and land equivalent ratio (LER) in different crop systems 431 at harvest of both growing seasons.

\begin{tabular}{|c|c|c|c|c|c|c|c|}
\hline \multirow[t]{2}{*}{ Year } & \multirow[t]{2}{*}{ Planting mode } & \multicolumn{2}{|c|}{$\begin{array}{l}\text { Yield } \\
\left(\mathrm{t} \mathrm{ha}^{-1}\right)\end{array}$} & \multicolumn{2}{|c|}{$\begin{array}{l}\text { Economy }{ }^{\mathrm{g}} \\
\left(\mathrm{USD} \mathrm{ha}^{-1}\right)\end{array}$} & \multirow{2}{*}{$\begin{array}{l}\text { Intercropping } \\
\text { advantage }\left(\mathrm{t} \mathrm{ha}^{-1}\right)\end{array}$} & \multirow{2}{*}{$\begin{array}{l}\text { Land equivalent } \\
\text { ratio ( LER) }\end{array}$} \\
\hline & & Maize & Peanut & Maize & Peanut & & \\
\hline \multirow{2}{*}{2015} & Monoculture & $10.68 b$ & $4.37 \mathrm{a}$ & 2234 & 1943 & & \\
\hline & Intercropping & $8.62 \mathrm{a}$ & $1.49 \mathrm{~b}$ & 2113 & 466 & $2.58 \mathrm{a}$ & $1.15 \mathrm{a}$ \\
\hline \multirow{2}{*}{2016} & Monoculture & $10.04 \mathrm{~b}$ & $4.34 \mathrm{a}$ & 2027 & 1918 & & \\
\hline & Intercropping & $8.23 \mathrm{a}$ & $1.46 \mathrm{~b}$ & 1992 & 441 & $2.50 \mathrm{a}$ & $1.16 \mathrm{a}$ \\
\hline
\end{tabular}

Data were presented on a basis of per hectare monoculture/intercropping area.

${ }^{\mathrm{I}}$ Cost: Labor 436.68 USD ha ${ }^{-1}$ for maize and 545.85 USD ha ${ }^{-1}$ for peanut, Pesticides and herbicides 101.9 USD ha $^{-1}$ for maize and 94.6 USD ha ${ }^{-1}$ for peanut, Maize seed 1.90 USD kg-1, Peanut seed 0.87 USD kg-1, Resin-coated urea $480.3 \mathrm{USD} \mathrm{t}^{-1}$, Calcium superphosphate 109.2 USD t-1 , Potassium chloride 320.2 USD t$^{-1}$; Procurement price: maize grain $0.31 \mathrm{USD} \mathrm{kg}^{-1}$ in 2015 and $0.25 \mathrm{USD} \mathrm{kg}^{-1}$ in 2016, Peanut pod $0.73 \mathrm{USD} \mathrm{t}^{-1}$ in both years.

Table2 Effect of planting pattern on yield components of maize and peanut

\begin{tabular}{|c|c|c|c|c|c|c|c|}
\hline Year & Planting mode & \multicolumn{3}{|c|}{ Maize strip } & \multicolumn{3}{|c|}{ Peanut strip } \\
\hline \multirow{2}{*}{2015} & Monoculture & $8.6 \mathrm{a}$ & $373.9 \mathrm{~b}$ & $217.8 b$ & $73.5 \mathrm{a}$ & $27.3 \mathrm{a}$ & $64.2 \mathrm{~s}$ \\
\hline & Intercropping & $5.1 \mathrm{~b}$ & $454.3 \mathrm{a}$ & $238.9 \mathrm{a}$ & $66.0 \mathrm{~b}$ & $26.3 \mathrm{a}$ & $45.4 \mathrm{~b}$ \\
\hline 2016 & Intercropping & $4.8 \mathrm{~b}$ & $408.6 \mathrm{a}$ & $219.9 \mathrm{a}$ & $54.5 b$ & $26.0 \mathrm{a}$ & $43.6 \mathrm{~b}$ \\
\hline
\end{tabular}

Data were presented on a basis of per hectare monoculture/intercropping area.

Table3 Effects of planting pattern on 13C-photosynthates distribution in different organs (\%) at 24 hours after labelling

\begin{tabular}{|c|c|c|c|c|c|c|c|c|c|}
\hline \multirow{2}{*}{ Year } & \multirow{2}{*}{ Growth stages } & \multirow{2}{*}{ Treatment } & \multicolumn{7}{|c|}{${ }^{13} \mathrm{C}$-photosynthates distribution in different organs (\%) } \\
\hline & & & Ear leaf & Stem & Other leaves & Cob & Ear bracts & Tassel & Grain \\
\hline \multirow{4}{*}{2015} & \multirow{2}{*}{ DAS } & SM & $3.60 \mathrm{~b}$ & $50.32 \mathrm{~b}$ & $28.55 \mathrm{a}$ & $5.91 \mathrm{a}$ & $9.65 b$ & $1.97 \mathrm{a}$ & - \\
\hline & & $\mathrm{IM}$ & $4.14 \mathrm{a}$ & $52.85 \mathrm{a}$ & $22.96 b$ & $4.56 \mathrm{~b}$ & $13.85 \mathrm{a}$ & $1.64 \mathrm{~b}$ & - \\
\hline & \multirow{2}{*}{ R6 } & SM & $2.50 \mathrm{a}$ & $18.17 \mathrm{a}$ & $11.73 \mathrm{a}$ & $7.64 \mathrm{a}$ & $5.69 \mathrm{a}$ & $0.42 \mathrm{~b}$ & $53.86 \mathrm{~b}$ \\
\hline & & $\mathrm{IM}$ & $2.06 \mathrm{~b}$ & $17.20 \mathrm{~b}$ & $10.81 b$ & $7.89 \mathrm{a}$ & $5.91 \mathrm{a}$ & $0.76 \mathrm{a}$ & $55.37 \mathrm{a}$ \\
\hline \multirow{4}{*}{2016} & \multirow{2}{*}{ DAS } & SM & $3.87 \mathrm{~b}$ & $50.97 \mathrm{~b}$ & $28.23 \mathrm{a}$ & $3.56 \mathrm{~b}$ & $11.73 b$ & $1.64 \mathrm{a}$ & - \\
\hline & & $\mathrm{IM}$ & $4.14 \mathrm{a}$ & $52.85 \mathrm{a}$ & $23.52 b$ & $4.55 \mathrm{a}$ & $13.25 \mathrm{a}$ & $1.68 \mathrm{a}$ & - \\
\hline & \multirow{2}{*}{ R6 } & SM & $1.88 \mathrm{a}$ & $20.03 a$ & $12.03 \mathrm{a}$ & $7.28 \mathrm{~b}$ & $4.52 \mathrm{a}$ & $1.65 \mathrm{a}$ & $52.63 b$ \\
\hline & & IM & $1.57 \mathrm{~b}$ & $18.69 b$ & $10.77 b$ & $8.13 a$ & $4.61 \mathrm{a}$ & $1.26 \mathrm{~b}$ & $54.98 \mathrm{a}$ \\
\hline
\end{tabular}


Figures

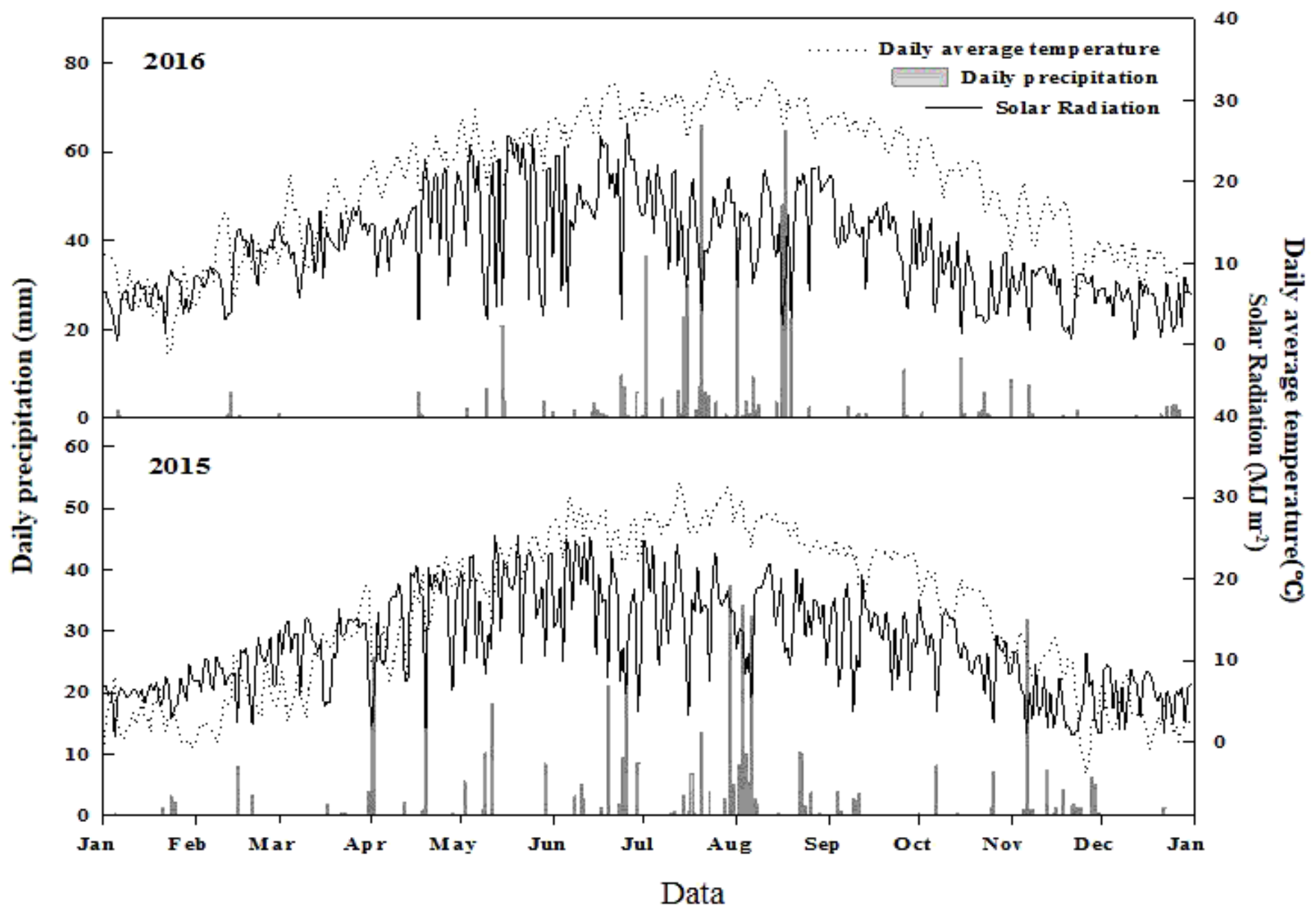

Figure 1

Annual meteorological data in 2015 and 2016

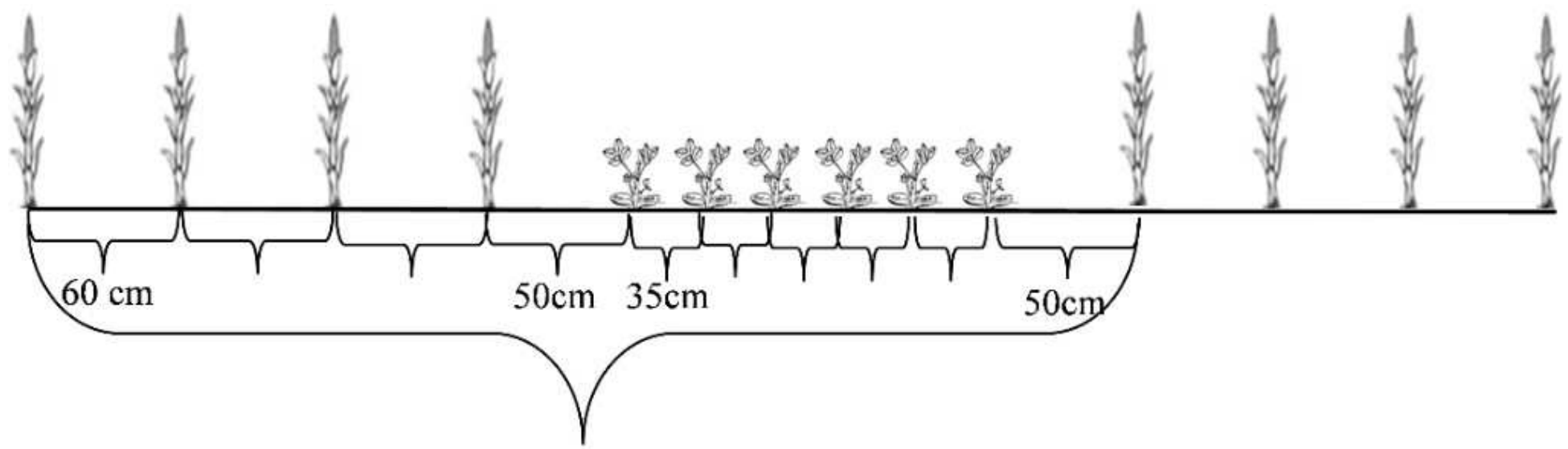

Distance: $455 \mathrm{~cm}$ 
Figure 2

Sketch map of maize-peanut intercropping pattern

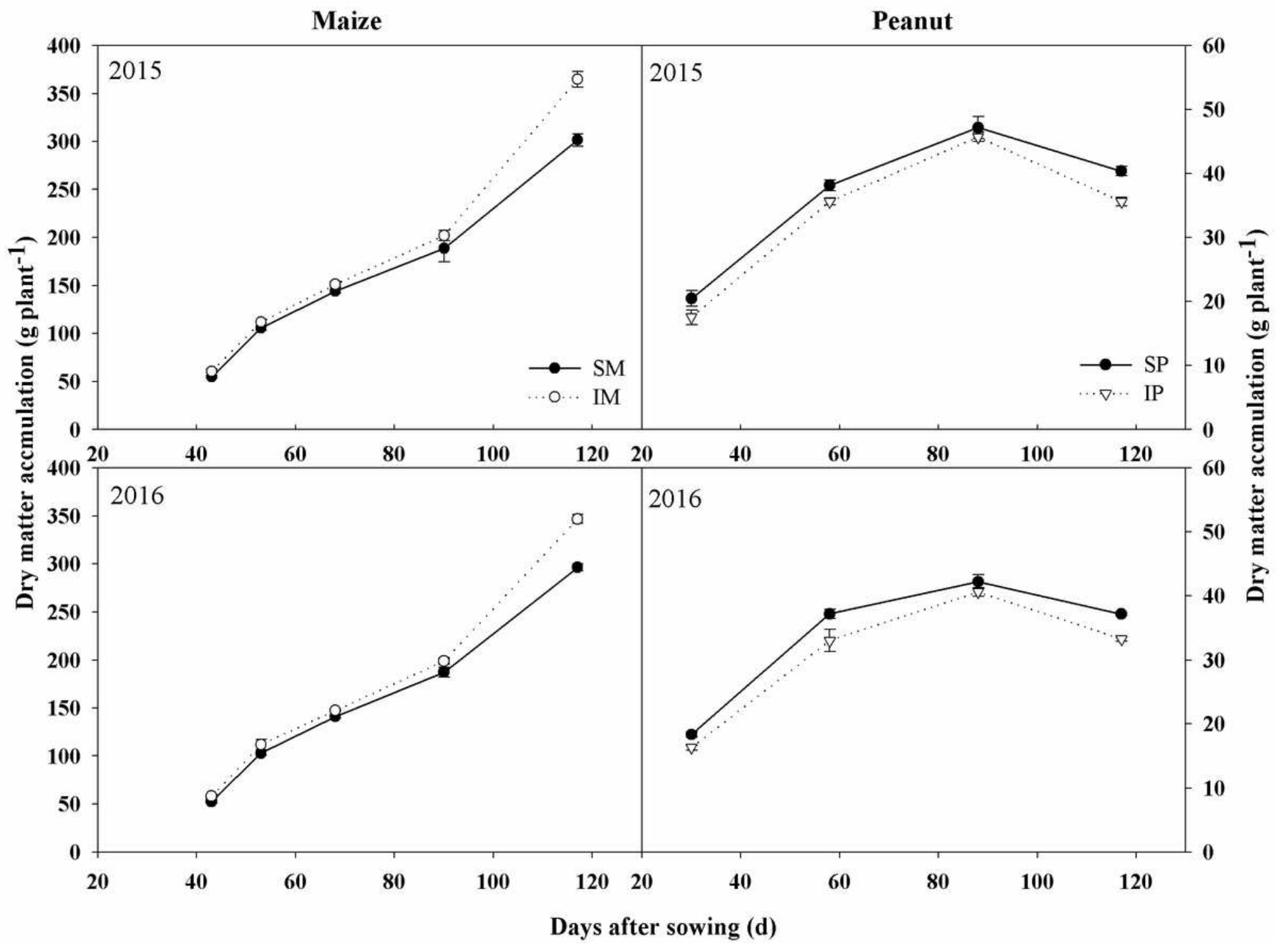

Figure 3

Effects of planting pattern on the dry matter accumulation per plant of maize and peanut (g plant-1) 


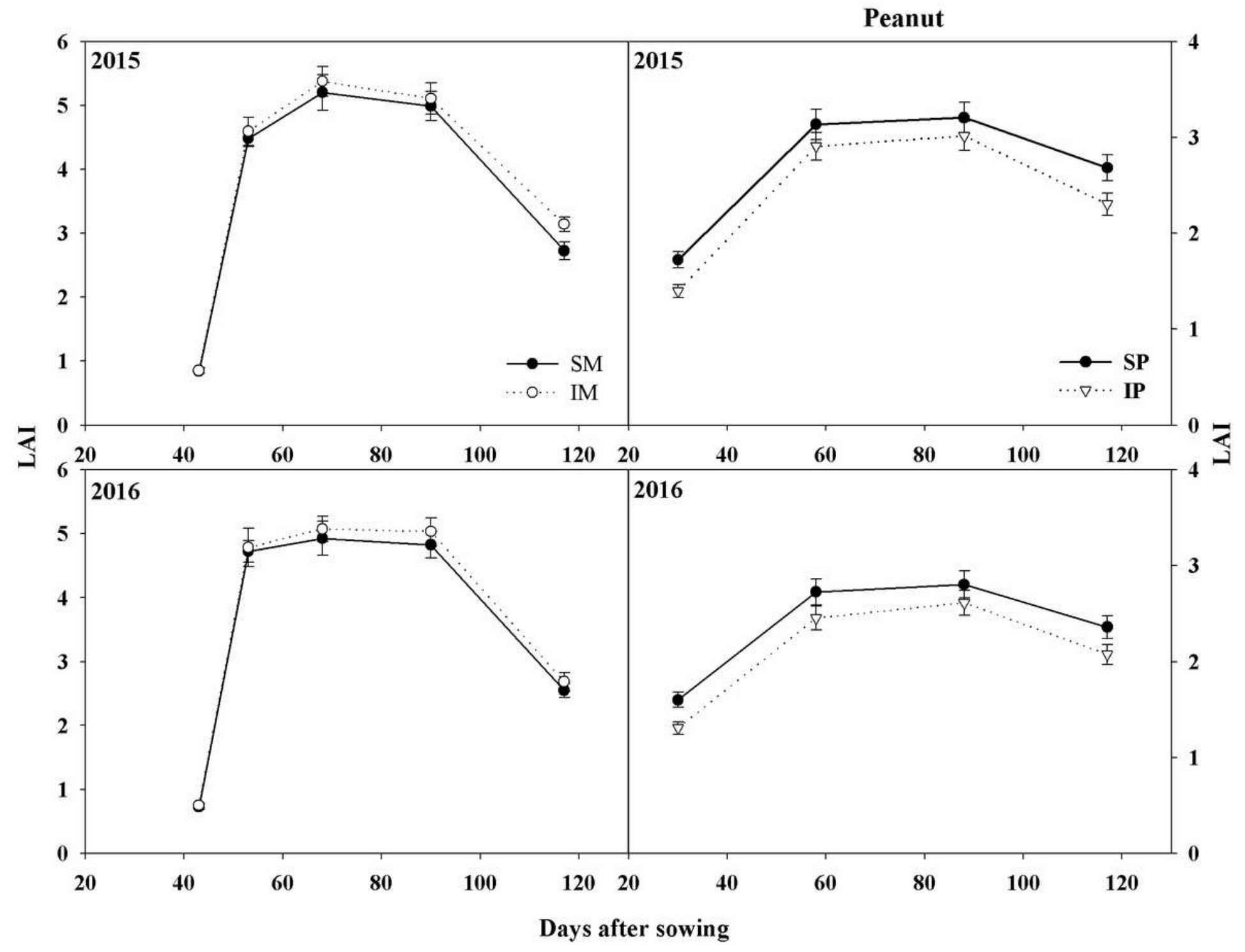

Figure 4

Effects of planting pattern on the LAl of maize and peanut 


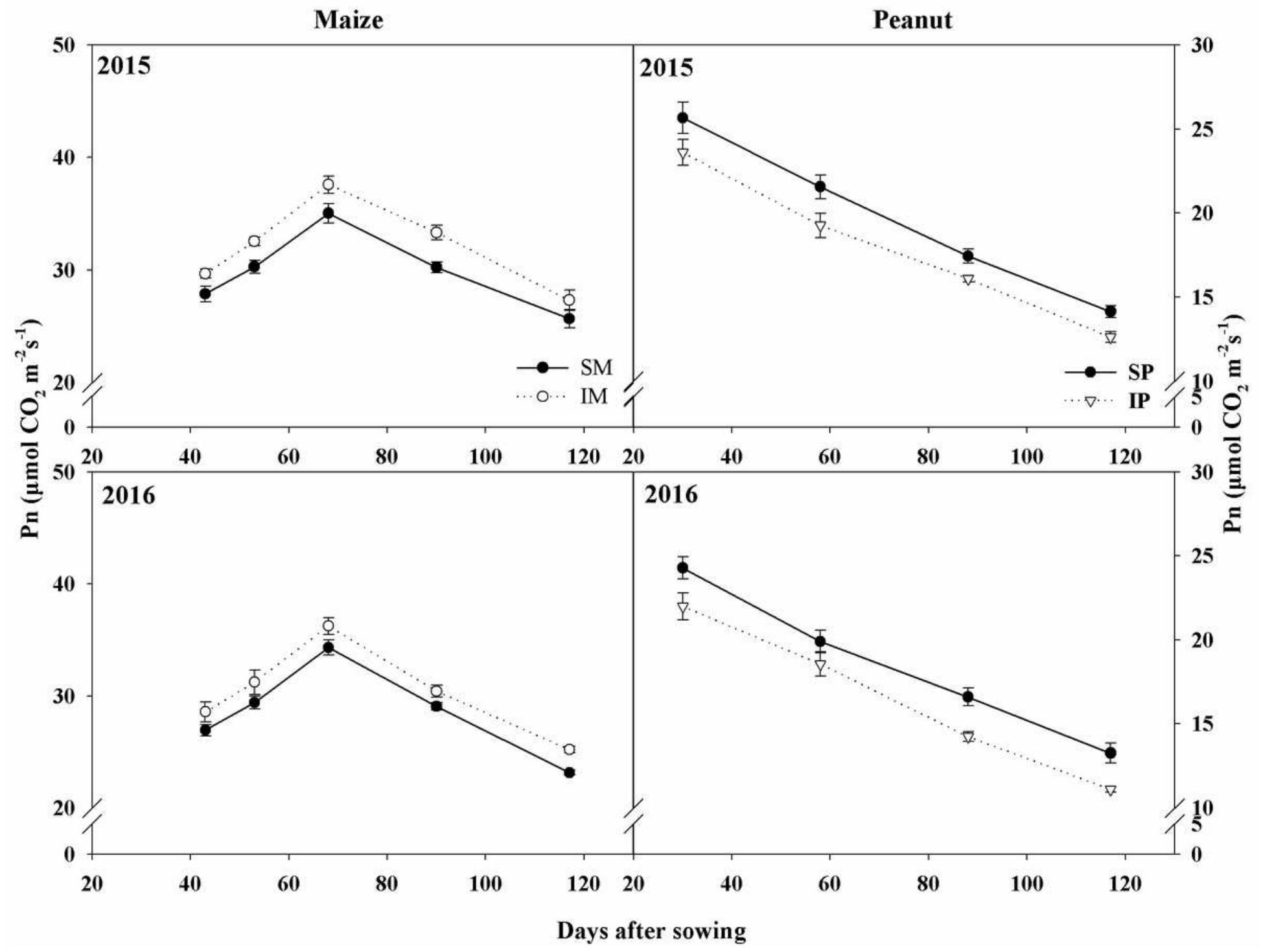

Figure 5

Effects of planting pattern on the net photosynthetic rate $(\mathrm{Pn})$ of maize and peanut 